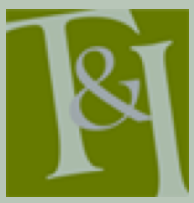

The International Journal for Translation \& In erpreting Research trans-int.org

\title{
Feedback on feedback: Guiding student interpreter performance
}

\author{
Jieun Lee \\ Ewha Womans University \\ jieun.lee@ewha.ac.kr
}

DOI:10.12807/ti.110201.2018.a09

\begin{abstract}
Feedback is an essential part of all types of teaching and learning and interpreter training is no exception. This paper examines the theoretical and practical aspects of the feedback that student interpreters receive and give according to a questionnaire-based online survey of fifty-eight students enrolled at a conference interpreter training programme in Seoul. The results indicate that the participants generally appreciate the feedback generated by teachers and peer interaction. However, they value and trust teacher feedback far more than peer feedback, considering it more comprehensive, authoritative and hence most effective. The data analysis also reveals that students seek teacher attention and support relating to both academic and emotional needs. The findings indicate that teachers need to facilitate students' learning through feedback, and that feedback is a complex task which requires further scholarly attention.
\end{abstract}

Keywords: interpreter training, teacher feedback, peer feedback, selffeedback, autonomous learning

\section{Introduction}

Many interpreter trainers are former trainees themselves, and they often tend to follow in their own trainer's footsteps, adopting the former's teaching styles or teaching intuitively, expecting such teaching strategies to be effective. However, teachers always need to ask themselves whether or not they are pursuing best practice strategies, hence the importance of research-based teaching practice. This paper was motivated primarily by curiosity relating to the feedback process in interpreter training, and examines common feedback practices in order to determine which types of feedback are considered effective from a student perspective.

In any field of interpreter training based on skill development through various forms of interpreting exercises, the provision of effective feedback plays a central role (Kwark \& Hong 2012; Lim 2014; Setton \& Dawrant 2016). Feedback in the course of interpreter training can take many forms, but is basically teacher-generated, peer-generated or self-generated. It is typically based on quality assessment criteria such as accuracy (i.e., source-target correspondence), the adequacy of target language choices, and delivery (e.g., Schjoldager 1996; Lee 2008; Riccardi 2002). Raising awareness both of such 
quality standards and of deviations from expected norms is a critical part of professional interpreter training. It is also important to provide information and advice on specific strategies and solutions and on how to cope with challenges during training (Ficchi 1999: 206; Setton and Dawrant 2016: 36).

In a learner-centred teaching environment, the teacher's role is to facilitate learning and skill acquisition by offering effective pedagogical support for students to become autonomous learners. ${ }^{i}$ As autonomous learners, students take responsibility for their own learning process and actively engage in reflective practice, relying on teachers to set clear course goals and objectives, and implement these through appropriate learner-centred classroom strategies (see Victori \& Lockhard 1995; Ficchi 1999; MoserMercer 2008.)

For skill acquisition and development, student interpreters are strongly encouraged to undertake conscientious efforts both in class and outside of class, practicing through self-study or pair/group work. For the sake of effective training, such practice should be tailored to the individual needs of students and should work in parallel with classroom activities in order to automate the skills practiced in class (Horváth 2007: 111). Outside of class practice, students decide on their own learning activities and bear responsibility for the learning process, thus making learning even more learner-centred (Horváth 2007: 116; Lim 2014: 190).

There is ample evidence of the benefits of feedback, which is widely adopted in interpreter and translator training as well as in language education (Liu and Carless 2006; Moser-Mercer 2000; Wang \& Han 2013). As mentioned above, depending on its source, feedback can be divided into teacher feedback, peer feedback, and self-feedback. Peer feedback, which is a hallmark of collaborative learning, aims to exchange and share ideas amongst students, and is a valuable means of stimulating learning motivation, selfesteem, and positive relationships among learners (Kiraly 2000: 37). Peer feedback also helps to moderate the teacher-dependent master-apprentice model of learning that has characterised interpreter training worldwide for decades, and is especially effective in developing metacognitive skills (MoserMercer 2008: 10), ${ }^{\text {ii }}$ thus enabling students to better monitor and direct their own learning. It can help students to see alternative perspectives on problems and to determine how these can be solved by other students. Such feedback is motivational in that peers, having experienced similar difficulties and challenges, may become more motivated and less inclined to indulge in [negative forms of] self-criticism. Because of the power asymmetry between teachers and students, it may be easier for the latter to accept critiques of their work from their peers rather than from their teachers (Värlander 2008: 151). In practical terms, peer feedback can be provided more quickly and be more accessible than teacher feedback, and may not invoke the anxiety often associated with teacher feedback (Liu and Carless 2006). Thus peer feedback is not necessarily of lower quality than teacher feedback (see Hamer et al. 2015).

\footnotetext{
${ }^{\mathrm{i}}$ Autonomous learning is defined as critical thinking, planning and evaluating learning, and reflection, which require effort on the part of the learner to continuously monitor the learning process (Horváth 2007: 104). It is concerned with learners' choices regarding learning management and selecting learning materials, methods, the place and time of learning, partners, etc. (Horváth 2007: 104).

ii "Metacognition refers to learners' awareness of their own knowledge and their ability to understand, control and manipulate their own cognitive processes" (MoserMercer 2008: 10-11).

Translation \& Interpreting Vol 10 No 1 (2018) 
By giving feedback to and receiving it from their peers, students may develop an appreciation of what counts as quality performance (Sadler 1989) and take an active role in the management of their own learning (Liu and Carless 2006). Collaborative learning boosts students' interests and critical thinking, and reinforces social skills through interactions because it often requires negotiation between learners of different levels of competence with respect to the goal, process and methods of learning and social relations. For the same reason, it may occasionally give rise to tensions and conflicts. Furthermore, the absence of a teacher affects peer interactions and may sometimes lead to inefficient and ineffective practice sessions, especially when students are new to interpreting training and are not given sufficient guidance on how to do it properly (Lim 2014: 193-194). In addition to time management issues, students' lack of language proficiency and interpreting skills might impede adequate feedback, which in turn delays or prolongs the practice session and negatively influences mutual trust among learners regarding peer feedback (Lim 2014). Therefore, it is necessary for teachers to pay attention to the contents of the feedback provided by students, as it is dependent on their source text comprehension and awareness of the criteria of quality in interpreting (Bartłomiejczyk 2007).

Students are also advised to analyse their own performance, which helps them to discover their weaknesses and strengths and channel their resources accordingly during training (Van Dam 1989; Russo 1995: 75). This is part of a highly targeted form of individual training, namely, deliberate practice (Setton \& Dawrant 2016: 47), which is critical to achieving a high level of skill mastery. In this paper, self-feedback refers to self-review or analytic assessment based on critical listening to one's own audio- or video-recorded performance. Through such reflective practice, student interpreters have opportunities to evaluate themselves and redo their performance until they can deliver a satisfactory rendition.

External feedback by teachers and peers is important as it may augment, concur or conflict with the student's interpretation of the task and the path of learning (Nicol \& Macfarlane-Dick 2006: 202). Internal feedback generated by one's own monitoring of current progress against desired goals affects the cognitive, motivational and behavioural aspects of performance and is perhaps more important to autonomous learning (Nicol \& Macfarlane-Dick 2006: 202). However, self-feedback has its limitations because it may be constrained by individual students' awareness of the interpreting quality criteria and their own metacognitive abilities, and hence needs to be regularly checked by their teachers as well as their peers and seen in perspective.

Different types of feedback contribute to learning, although perhaps to varying degrees. Although feedback is a key aspect of interpreter training, there is a dearth of research on feedback in interpreter training, let alone students' perspectives on feedback. Given that students' input is also a valuable resource which helps teachers reflect on their teaching practice, it is worthwhile to examine students' feedback on feedback they themselves receive during their interpreter training (Takeda 2010).

Against this backdrop, this paper seeks to investigate student interpreters' perspective on feedback and its perceived effect on their learning. The research findings are expected to provide insight into our everyday teaching and learning, and guide us in how we can further assist our students in a more effective way that is conducive to their learning and skill development. 


\section{Feedback}

Feedback is commonly defined as information provided by an agent (e.g., teacher, peer, book, self) to a learner regarding certain aspects of his or her performance (Hattie \& Timperley 2007; Duijnhower 2010). It is an important facilitator of all types of learning and performance (Bandura, 1991; Shute 2008; Hattie 2012) and a fundamental aspect of teaching and learning (Voerman et al. 2014; Hattie 2012). Feedback is aimed at closing the gap between the current performance and a specific goal (Hattie \& Timperley 2007; Sadler 1989; Shute 2008).

The feedback that is of interest in this paper concerns qualitative and formative feedback. Qualitative feedback is provided by means of (textual) comments, whereas quantitative feedback is provided in terms of numerical marks (Hamer et al. 2015: 152). Formative feedback addresses the accuracy or adequacy of a learner's task and may touch on particular errors and misconceptions (Shute 2008: 154). Such feedback can be either formal or informal. Formal feedback occurs with reference to a specific curricular assessment task, whereas informal feedback is not specifically stipulated in the curriculum and can occur in the course of various learning activities, often involving instantaneous feedback (Värlander 2008: 149).

Feedback plays an important role in learners' motivation and behaviour in classrooms by providing them with opportunities to learn and encouraging them to achieve their goals (Bangert-Drowns et al. 1991; Shin et al. 2016: 21). A review of the literature reveals that feedback is a not a simple concept, but is in fact made up of a number of elements. The interplay between different aspects of feedback is well conceptualised in the "feedback triangle" described by Yang and Carless (2013: 287). Their notion of feedback has three dimensions: the cognitive dimension (i.e. the content of feedback), the socialaffective dimension (i.e. the interpersonal negotiation of feedback) and the structural dimension (i.e. the organisation of feedback provision). The dynamic interplay between these elements is vital to the enhancement of feedback processes (Yang \& Carless 2013: 287). The cognitive dimension may include technique, strategy, procedure or other aspects of the quality of student work (Yang \& Carless 2013: 288). Feedback should focus students' attention on how to tackle problems effectively, how to increase their capacity to self-regulate, and how to use feedback productively to guide them to apply knowledge and skills (Yang \& Carless 2013: 289). Meanwhile, the socialaffective dimension is concerned with the social and interpersonal negotiation of feedback and how feedback conveys messages about learners' social role in their learning environment and how their emotions are engaged (Yang \& Carless 2013: 289). Finally, the structural dimension includes timing, sequencing and modes of feedback, which relate to how feedback processes are organised and managed by teachers and institutions (Yang \& Carless 2013: 289).

The literature indicates that the quality and quantity of feedback provided to learners influence what they eventually incorporate into their interpreting competence. For feedback to be effective, its function, content, and mode of presentation are important factors that should be considered in combination with learner characteristics and instructional variables (Narciss \& Huth 2004; Shute 2008: 176). The main functions of feedback are directive (i.e. telling the learner what needs to be fixed) and facilitative (i.e. suggestions to help guide students in their own revision and conceptualisation) (Shute 2008: 157). Timely and regular feedback is considered useful (Bangert-Drowns et al. 1991; Scott 2014: 50), however, the content of feedback seems to matter the 
most in terms of the effectiveness of feedback interventions (Bangert-Drowns et al. 1991; Golke et al. 2015: 124). Effective feedback is described as specific and goal-related (Voerman et al. 2014). Studies have shown that feedback is more effective when it offers detailed information on how to improve task performance rather than simply indicating accuracy or adequacy (BangertDrowns et al., 1991; Pridemore \& Klein, 1995). Vague feedback lacking in specificity may have little effect or little use (Wiliam 2007; Shute 2008).

The mode of feedback or the type of feedback presentation can be in person or mediated by technology. Teachers can directly monitor the class performance of students and give immediate feedback afterwards or provide written or oral feedback after listening to recordings outside class (Setton and Dawrant 2016: 37). Written feedback, which is usually a product of careful consideration and analysis, can be stored for later reference to monitor progress in terms of skill development (Bartłomiejczyk 2007: 264). Although computer-mediated feedback may not be as effective as face-to-face feedback, technology-enhanced feedback, which enables flexible feedback provision, does seem to hold promise for the future (Yang \& Carless 2013: 292). Recent studies reflect learners' positive reception of online feedback (Yang 2012; Lee et al. 2015). Employing web-based learning management systems in interpreter training helps facilitate feedback and interactions between teacher and learners and thus enhances the benefits of collaborative learning (Lee et al. 2015: 137).

Finally, different students can be expected to react differently to feedback. For instance, learners receiving feedback may respond to it differently emotionally depending on their relationship with the person providing the feedback and depending on the context. ${ }^{\text {iii }}$ Emotions are a natural part of learning and may, in the context of feedback situations, contribute to students' future motivation and self-esteem (Värlander 2008: 154). By contrast, critical or controlling feedback tends to be demotivating and tends to discourage learners from trying to improve their performance (Fedor et al. 2001).

In addition to individual idiosyncrasies and class dynamics, culture may come into play in feedback situations. For example, while students from collectivist cultures - including Asian - prefer indirect and implicit, groupfocused feedback, students from individualist cultures prefer more direct feedback and individual focused, self-related feedback (De Luque \& Sommer 2000). Despite a plethora of research on feedback, the mechanisms relating feedback to learning remain uncertain (Shute 2008: 156), and this gap in the literature calls for more scholarly investigation into feedback and learning in interpreter training.

\section{The study}

In order to examine student interpreters' perspectives on various types of feedback they received as well as the effect on their learning, a questionnaire was designed, consisting of 21 closed, multiple-choice questions and two open-ended questions. The survey was administered to students attending a

iii Emotions can be regarded as a product of individual experiences and also products
of social relationships between peers and between peers and teachers (Värlander 2008:
149). Motivated students may "appreciate and consult teachers who do not hold back
from frank and detailed feedback and offer constructive feedback even if she does not
necessarily offer an immediate quick-fix solution" (Setton and Dawrant 2016: 38).
Translation \& Interpreting Vol 10 No 1 (2018) 
two-year MA programme for conference interpreter training in South Korea near the end of the fall (autumn) semester in 2015. The Google survey link was sent to student class leaders, who were requested to invite their class mates to participate in the survey. Due to the way the study was designed, it is not known how many students actually received the invitation, however 58 student interpreters completed the survey, and their responses constituted the data for this study. ${ }^{\text {iv }}$ The student participants were specialising in interpreting between Korean and four other languages: English, Chinese, Japanese and French. As to the composition of the sample, English-Korean interpreting majors represented a slight majority (55.2\%), while Chinese majors formed the second largest group (20.7\%), followed by French (15.5\%) and Japanese $(8.6 \%)$ majors. Just over half of the students $(53.4 \%)$ were finishing their second year of training, while the remaining $46.6 \%$ had nearly completed their first year of training at the time of the survey.

The survey asked the students to evaluate the effect they felt various types of feedback had had on them, and this included peer feedback, teacher feedback, and self-review. They were also asked about their preferred types of feedback and to comment on what they had found to be the most helpful and memorable feedback during their training. A quantitative analysis of the data is followed by qualitative analysis.

\subsection{Quantitative data analysis}

The participants were generally satisfied with the feedback they had received, with $17.2 \%$ responding that they were very satisfied with it. This left $55.2 \%$ who were highly satisfied, and $22.4 \%$ who were satisfied overall. Only $5.2 \%$ of respondents indicated a low level of satisfaction, while none of the respondents selected a 'very low' level of satisfaction.

\subsubsection{Peer feedback}

Participants were asked to evaluate peer feedback in both in-class and out-ofclass practice sessions. They were asked to indicate the perceived effect of peer feedback on helping to improve their interpreting performance on a 5point scale (from very low to very high). The results are presented in Figure 1.

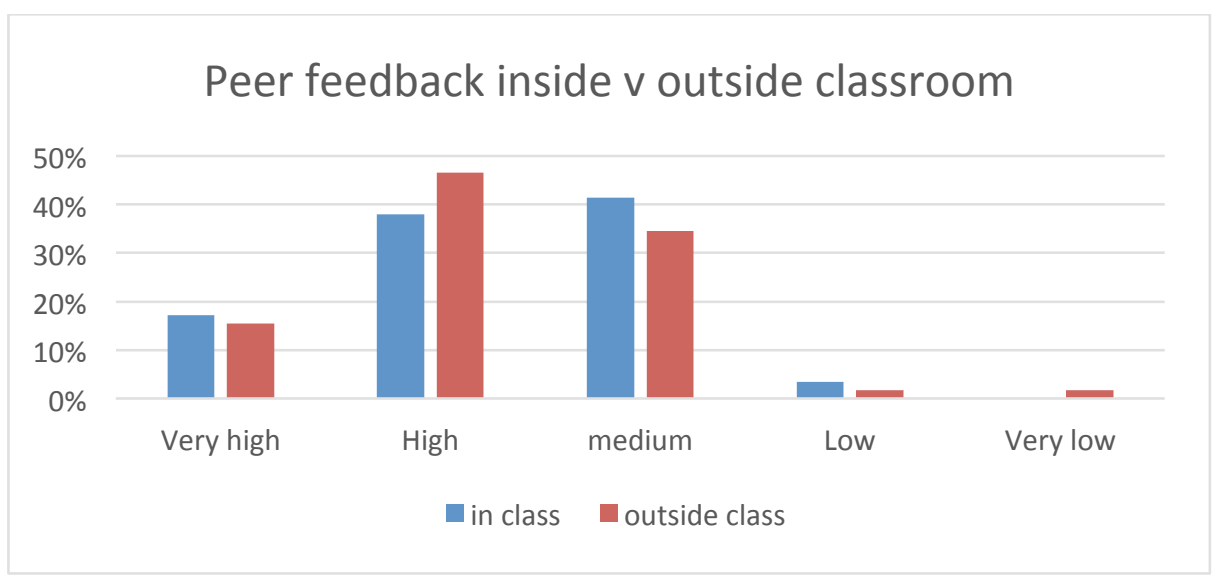

Figure 1: Perceived effect of in-class peer feedback vs outside-class peer feedback

iv A total of 136 students were enrolled at the time of the survey. 
More than half of the participants stated that in-class peer feedback had had a strong effect on their learning, with $37.9 \%$ choosing 'high', and $17.2 \%$ selecting 'very high'. A considerable number of respondents $(41.4 \%)$ said they felt this type of feedback had had a 'medium' effect, while only $3.4 \%$ felt that the effect of their peers' feedback during classes had been 'low'.

In total, $81 \%$ responded that in-class peer feedback had been actively exchanged, however almost one fifth of respondents (19\%) disagreed. As to the reasons for less than active peer feedback, the students responded that it might be due to their failure to identify problems or difficulties in providing suggestions (30.4\%). Face-saving also played a role: a total of $17.4 \%$ said that they were unwilling to lose face by offering inadequate feedback, and $13 \%$ said that they did not want to hurt others' feelings. Another 17.4\% pointed to a generally passive class environment where feedback was not mandatory, while $8.7 \%$ indicated that this was due to a lack of confidence in providing feedback because of the presence of a teacher. The remaining $13 \%$ chose 'other' but did not comment further.

With respect to peer feedback provided outside of the classroom, over half of the respondents felt that the effect of peer feedback during practice sessions on their learning had been very high or high $(15.5 \%$ and $46.6 \%$, respectively), while another $34.5 \%$ described the effects as 'medium'. Few thought that such feedback was not effective. Those who assessed the effect of peer feedback given outside of the classroom as 'medium' commented that they often became side-tracked from their practice, chatting and not managing their time efficiently (see also Lim 2014). On the other hand, those who provided a positive evaluation explained that they received more and also more thorough feedback during private practice than during class. This result may have been due to the fact that students were able to choose their practice partners and were less affected by time constraints. The absence of the teacher may also have been a factor in that students may have felt free to exchange ideas and opinions.

When asked which aspects of in-class peer feedback were most important, the students stated that they wanted corrections with suggestions for alternative expressions (72.4\%) rather than simple error detections $(17.2 \%)$. Only a few students said they wanted emotional support (3.4\%) and to have their choice of strategies confirmed or to be complimented on a job well done $(1.7 \%)$.

As for outside-class peer feedback, the order of their preferred choices remained the same, however less respondents stated they wanted suggestions for alternative expressions (58.6\%), with more stating they would like error detection $(27.6 \%)$ compared to students' assessments of in-class peer feedback. It is difficult to pinpoint specific reasons for this, however respondents' general comments suggest that this was due to respondents' awareness of their peers' competence, which may be why they tended to be content with feedback focusing on error correction.

\subsubsection{Teacher feedback}

The results indicate that the participants valued teacher feedback the most. When asked to assess the effect of teacher feedback on their learning, 58.6\% chose 'very high', while $32.8 \%$ selected 'high', and $8.6 \%$ 'medium'. Student comments, indicated that they felt teacher feedback was far more valuable than peer feedback in terms of its impact on their learning (see Figure 2). 


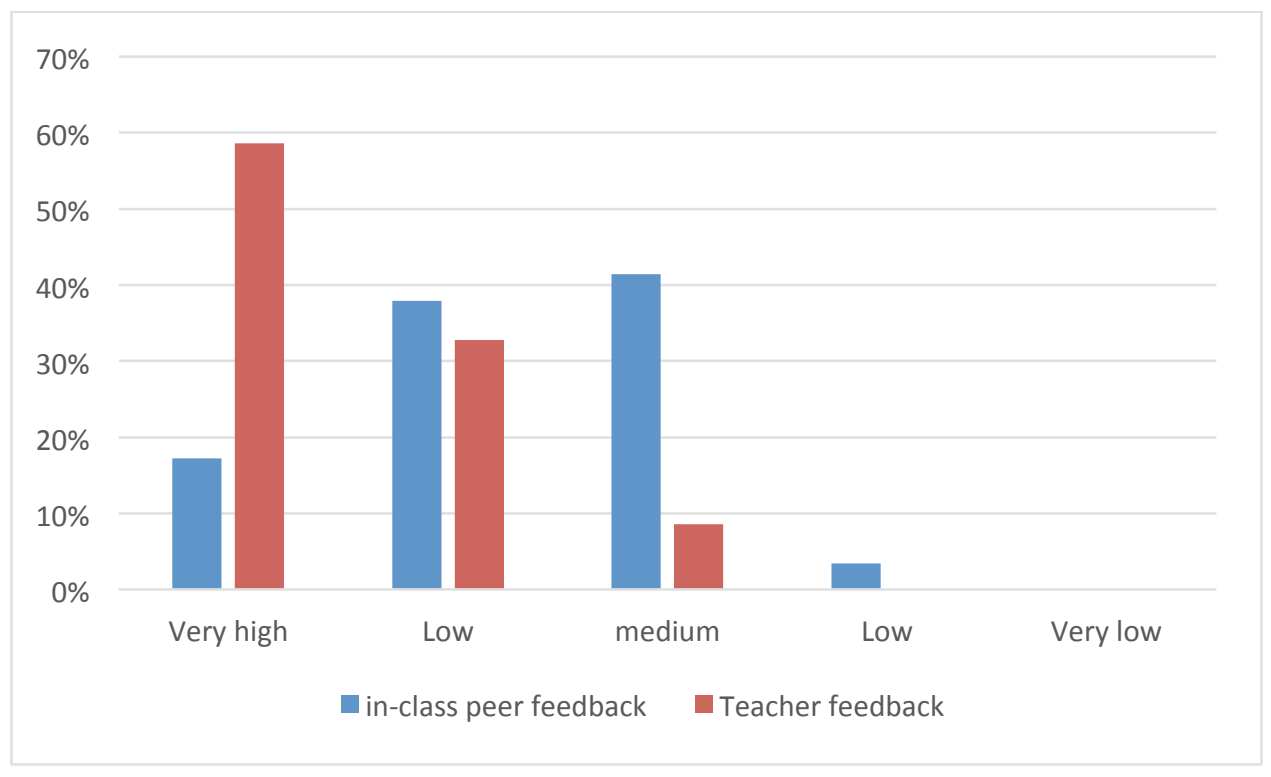

Figure 2: Perceived effect of in-class peer feedback vs teacher feedback

Almost two thirds of respondents (63.8\%) felt the suggestion of alternative expressions was the most important aspect of teacher feedback, while $20.7 \%$ chose 'pointing out problems', with $6.9 \%$ choosing 'emotional support', and 3.4\% selecting 'confirmation of a job well done/well-interpreted sections'. The remaining $5.2 \%$ chose 'other'. When asked why teacher feedback was considered more important than peer feedback, $52.5 \%$ said that teacher feedback was insightful and analytic, while $31.3 \%$ responded that they trusted the teachers' expertise, and $13.1 \%$ stated that teacher feedback complemented peer feedback.

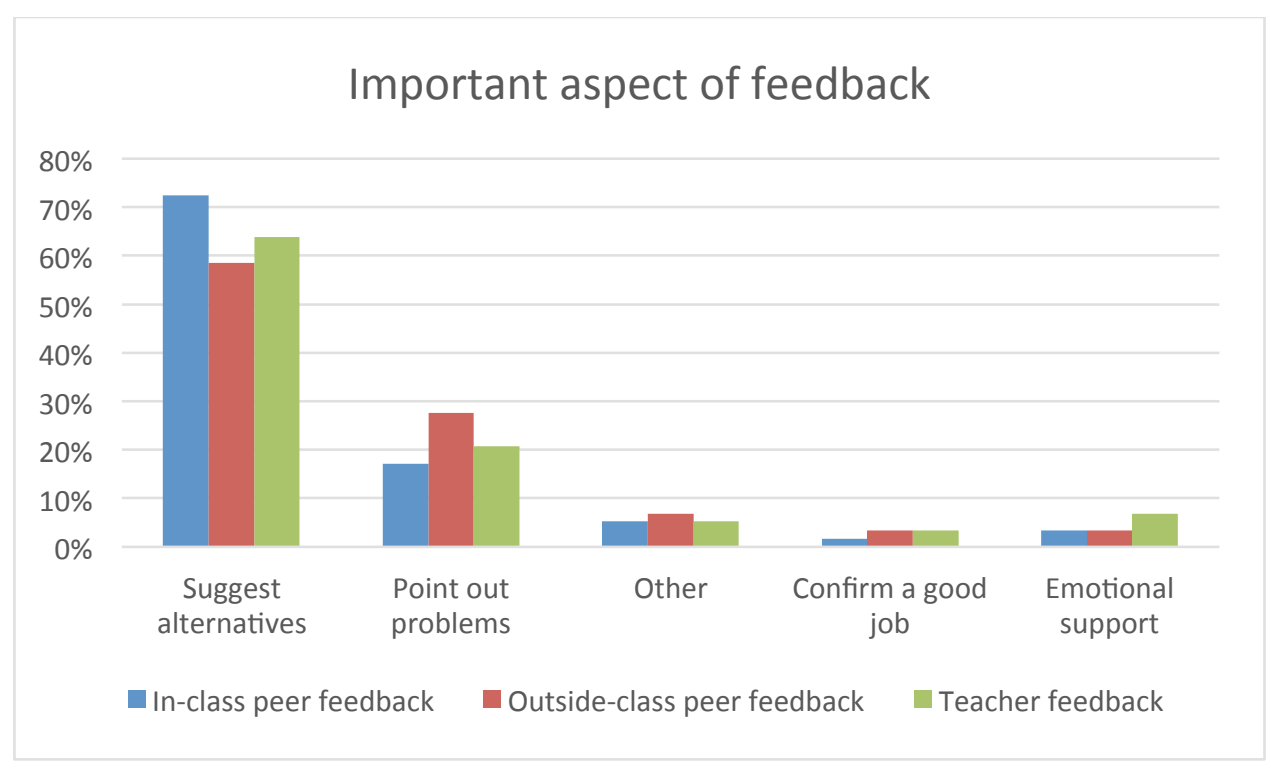

Figure 3: Important aspects of different types of feedback 
Overall, participants' perceptions remained the same regardless of when they received the feedback and who provided the feedback. They thought that feedback should include solutions, namely, suggestions of better or alternative ways to phrase something in the target language, in addition to error correction. However, students tended to value error detection comments received during out-of-class practice as more important than similar comments received in-class (see Figure 3). The numbers were small, but it would appear that teachers - more so than peers - were expected to consider how their feedback would affect students' feelings, paying attention to such emotional aspects as well. (see also Figure 3).

\subsubsection{Self-review based on audio/video recordings}

The survey asked if participants had audio/video-recorded their interpreting and most respondents had done so for review purposes (94.8\%). Participants agreed that reflective practice through analysis of one's own audio-recorded performance was effective, with $50.9 \%$ evaluating its perceived effect as 'very high', while $29.8 \%$ of respondents assessed its effect as 'high', and $19.3 \%$ as 'medium'. None chose 'low' or 'very low'. Given that consecutive interpreting can be recorded on video for detailed analysis, which allows consideration of delivery aspects such as posture, eye contact, facial expressions, and hand movements (Setton and Dawrant 2016: 38), it may be a very effective tool to draw students' attention to the whole package of professional interpreting. The data presented here suggest that fewer respondents regularly video-recorded their interpreting performances than audio-recorded them, and that they were less positive about the perceived effect of video-based self-reviews (see Figure 4). The 'medium' effect option was chosen by the largest number (38.2\%) of participants, whereas $25.5 \%$ chose 'very high', with $29.1 \%$ choosing 'high', and $7.3 \%$ selecting 'low'. In fact, many of those who evaluated its effect as medium or low had never tried video-recording their performances, so their assessment was presumably based on assumption rather than on first-hand experience.

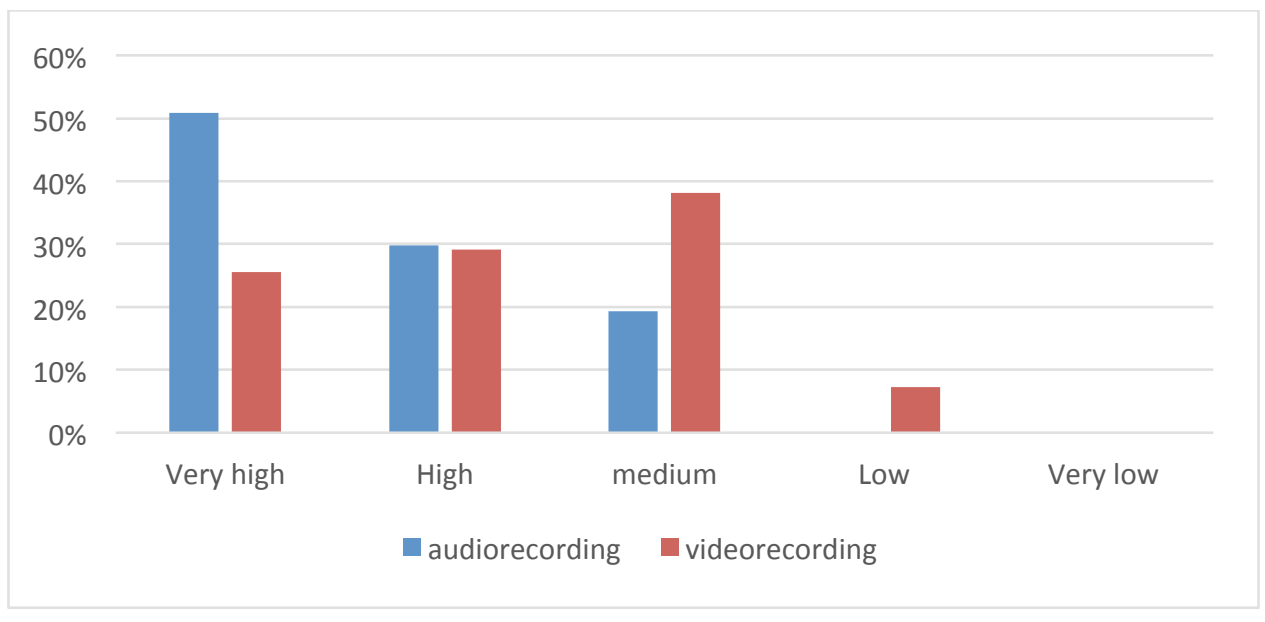

Figure 4: Perceived effect of self-review based on audio recording vs video recording 


\subsubsection{Preferred feedback types}

In terms of perceived effect, the findings indicate that teacher feedback surpassed all other types of feedback, both self-review and peer feedback. The horizontal axis indicates the evaluation of feedback, namely, the perceived effect on participant learning (ranking from 1: very low to 5: very high), while the vertical axis shows different types of feedback (1: in-class peer feedback, 2: teacher feedback, 3: self-feedback based on audio recording, 4: selffeedback based on video recording, and 5: outside-class peer feedback). The plot box demonstrates that teacher feedback and self-feedback based on audio recordings were considered more effective than other types (see Figure 5).

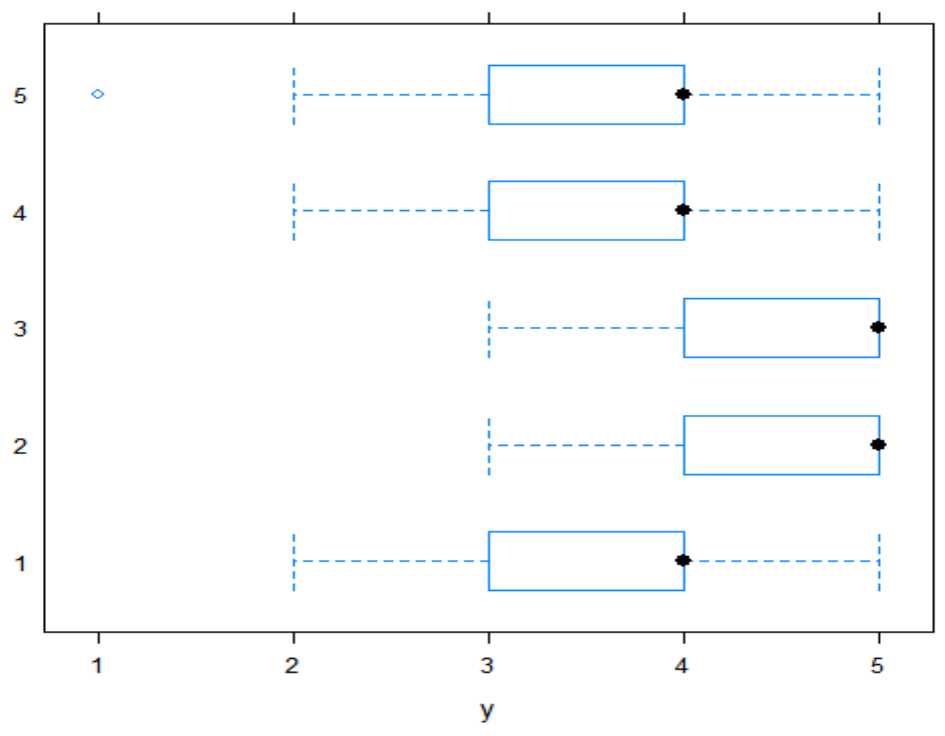

Figure 5: Feedback evaluation in terms of the effect on student learning

When asked to choose which type of feedback they preferred, the participants were divided in their opinions, with $58.7 \%$ choosing 'detailed feedback', while $41.4 \%$ chose 'feedback on important issues only' (see Figure 6). While $51.7 \%$ wanted to receive 'feedback in consideration of their feelings', $48.3 \%$ preferred 'harsh critique'. As to their preference for guidance and suggestions of model expressions or concrete alternatives, $89.7 \%$ of respondents said that they liked to be guided to find an answer on their own, whereas only $10.3 \%$ said that they wanted to receive -model - alternative expressions.

With respect to the mode of feedback, the participants strongly preferred oral feedback to written feedback ( $81 \%$ vs $19 \%)$. Oral feedback may be provided both face-to face in classroom settings or after class. It may also be given in non-face-to-face settings for instance by way of audio-recorded feedback sent by email after the class. Written feedback may be provided in various manners, usually after class, in the forms of written feedback on interpreting assignments, namely comments on transcribed interpreted texts, comments by email or text messaging, or online comments on a Moodle-based Learning Management System (LMS). When asked to choose the three most preferred types of teacher feedback, face-to-face feedback was chosen by $46.4 \%$ as the most preferred out of five possible feedback types, while $28.9 \%$ 
of respondents stated they preferred written feedback on the transcripts of interpreted renditions (in a Word document) the most, and the remaining $24.7 \%$ said they preferred email feedback.

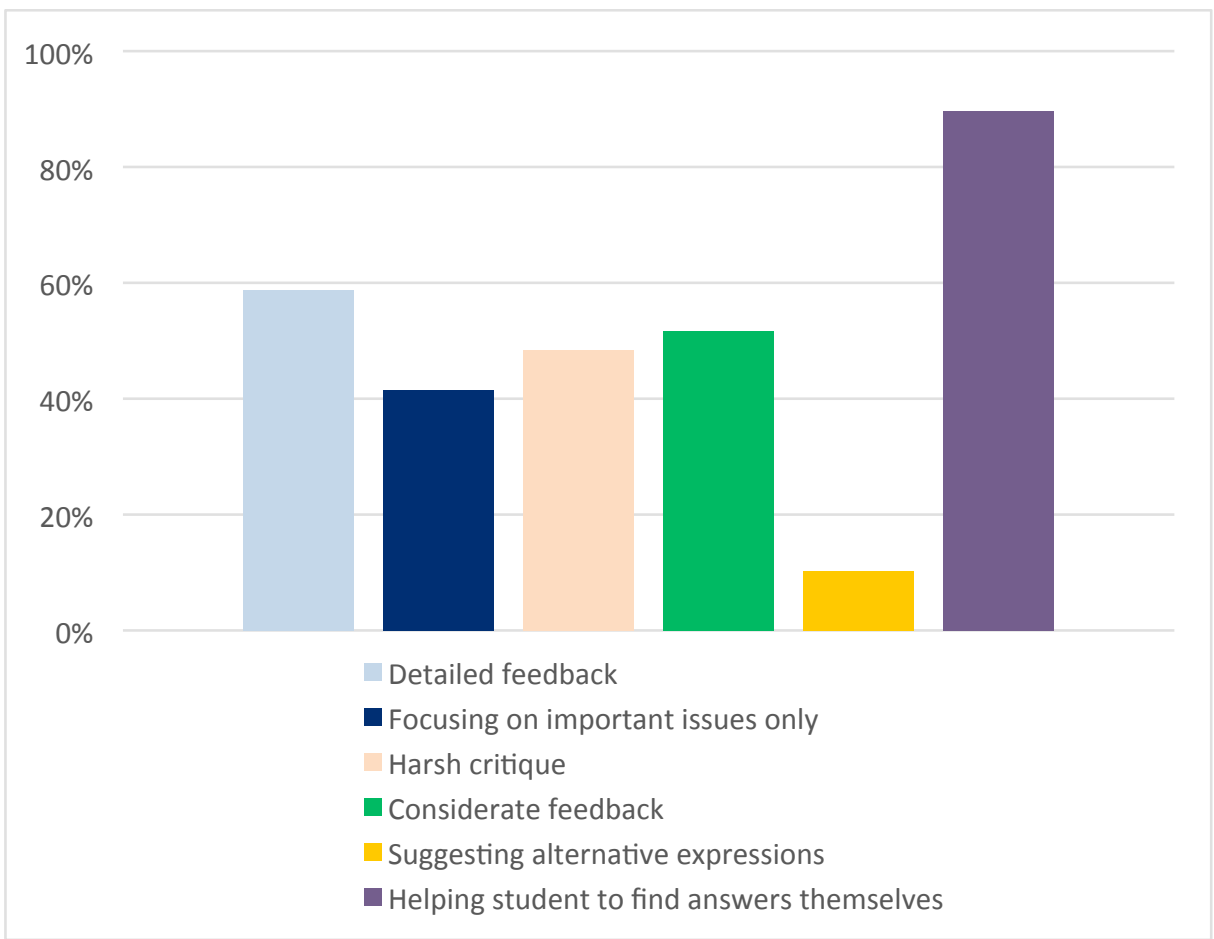

Figure 6: Preferred types of feedback

\subsection{Qualitative data analysis}

\subsubsection{Peer feedback}

As discussed above, few participants regarded the value of peer feedback as 'low', with a majority considering it critical to their training. Participant responses suggested that they had to rely on peer feedback in simultaneous interpreting classes in particular, since teachers cannot listen to multiple students' interpreting at the same time. Participants' comments indicated that they did not value in-class peer feedback as particularly better or worse than out-of-class feedback and that they certainly had learned from feedback received from their peers. One respondent wrote:

It is helpful to listen to others who have different perspectives and [I] find it helpful to receive diverse feedback. (R13)

Most of those who gave positive evaluations of peer feedback did not add comments, but those with a neutral attitude towards peer feedback left some comments. As some stated, peer feedback depends largely on the competence of individuals, such as bilingual proficiency, and not all feedback is useful, while it can be hurtful. Another negative aspect of peer feedback was associated with students' tendency towards micro-approaches that involved focusing on details rather than looking at the big picture. 


\subsubsection{Teacher feedback}

The students' comments revealed why they valued teacher feedback so highly. The participants most frequently stated that teachers provided quality feedback, identified problems missed by students and offered suggestions or solutions. Participants felt that teachers, whom they considered to be experts with years of experience, were able to critique their performances with greater accuracy and point students in the right direction in their training. One student stated that listening to a teacher's feedback on renditions by other students (supposedly at the similar level of competence) was also helpful. Some participant responses are given below.

Teachers have different and broader perspectives and point to fundamental problems and effective study methods. (R7)

I can understand more clearly what I need to improve. (R21)

As they are experienced interpreters, their feedback will prepare us for practice after training. (R38)

Teachers' feedbacks are very accurate and sharp. (R39)

Teachers provide feedback on things students did not think of and offer several ways to practice to improve skills and solutions that we as students could not come up with. (R11)

Teacher feedback includes delivery aspects and is thus more comprehensive than peer feedback. (R19)

While peer feedback is focused on omission and target language expressions, teacher feedback covers a wider range of performance, including logical links in TT. (R44)

\subsubsection{Desirable feedback}

Participants provided a range of responses to the question of what kind of feedback they wished to receive. Although this question was not limited to teacher feedback, most answers focused on this type of feedback. Many students shared the view that they wanted to know both their weaknesses and strengths as seen from an objective point of view. In addition, several students wanted to receive feedback on their progress or lack thereof compared to previous renditions, instead of a one-off instance of feedback on their performance in a particular class.

I know what I'm lacking, but I'd also like to know what I'm good at. (R6)

I think my progress happens quickly when teachers comment on changes (progress or deterioration/retrogression) I may not be aware of. (R7)

A teacher's feedback on problems and analysis of possible causes helps in solving the problems, and modelling through demonstrating what good interpreting also helps. (R41)

Considerate and tactful feedback is sought by students:

Students are under enormous pressure to pass the advancement test at the end of the first year, so an empathetic critique would be greatly appreciated. (R6) 
Professors may have their own style of providing feedback. However, since we are studying under extreme anxiety and tension, a timely, encouraging comment is needed. Just a simple word can help students a lot. When I was thinking whether I should drop out or not, a professor commented kindly that I wasn't looking well, and that gave me such a comfort and changed my idea about quitting. (R12)

Too harsh or too complimentary feedback may not be useful, and a harsh critique with a little bit of positive feedback will be good. Instead of focusing on details, taking a macro viewpoint and checking the logical flow should come first. (R35)

Since students know too well that they lack skills, and a critique of poor performance may only be a stressor and a debilitating factor rather than a motivating one. Instead, confirmation of strengths and a good job done in combination with suggestions for alternatives and solutions will be greatly appreciated. (R39)

Detached, objective feedback (rather than harsh critique or encouragement) may not discourage students or inflate their pride. (R50)

Many students expressed their desire to have emotional support from teachers, but some stated their readiness to receive pointed and critical feedback for their development.

Given limited class hours, it is more efficient to focus on problems. (R10)

Professors take great cautions when giving feedback on performance so as not to hurt our feelings, but personally, I think it is okay for me to receive a harsh and stern critique for the sake of my skill improvement. (R5)

The data revealed that students generally wanted to receive specific guidance regarding problems and solutions including suggested practice methods. The responses also indicated that teachers had different approaches to feedback and some did not give detailed feedback on test performances.

I would like to receive suggestions on alternative ways to express the idea I struggled with. Even when I did a good job, if there are other possible ways, I'd like to know more about them. (R33)

It would be great if teachers took individualised approaches and suggested study methods because everyone has their own way of interpreting the same idea. (R17)

I want to have feedback on various aspects such as comprehension, notes, and speech production, not just on output quality. (R18)

I would like to have in-depth feedback on my midterm and final examination, including my strengths and weaknesses. (R49)

The respondents were also asked to relate the most helpful and memorable feedback they had received during their training. What they had found most memorable was in fact very similar to the feedback they wished to receive. In short, students preferred teachers to take into account the emotional aspects of feedback and offer comprehensive commentary, including concrete solutions and analytical comments. Since feedback can have powerful effects on students' self-confidence and emotions, both positively and negatively 
(Hounsell 2003; Voerman et al. 2014), teachers should consider the emotional aspects of providing comments, since the learning process is often painful and associated with much stress and feelings of frustration and fear of failure (Gile 2005: 139). See below for further comments.

It was very helpful when the teacher gave me feedback after my interpreting regarding where I made mistakes and where I did a good job. It was good to know what was good because I could apply that strategy afterwards. (R7)

It was most helpful when my teacher gave me compliments, reminding me of my strengths as well as my weak points and bad habits and advising me how to fix them. (R21)

The most memorable feedback I got was that I should make a cool-headed and accurate assessment of the cause of problems instead of making a judgement on the quality of output. (R33)

I think a teacher's feedback is most effective when she starts with emotional support and encouragement, gives constructive criticism, and finishes with encouragement to cheer me up. It provides me with emotional stability, and the will to step up exceeds negative feelings and discouragement. (R11)

I appreciated my teacher's feedback for supporting me when I struggled with fundamental problems and helping me recognise them on my own. (R1)

I liked it best when teachers demonstrated what to do and how to do it in specific situations. Rather than telling us in abstract terms, showing concrete ways was easier to understand and more convincing. (R16)

I appreciated empathetic feedback the most. I know I am lagging behind, so it wouldn't make me feel conceited even if I received an emotionally supportive critique. (R45)

Written feedback was well received by learners. It seems to be a powerful and effective method of communication. The following are some of the student comments concerning written feedback.

A teacher gave me written feedback based on my audio recorded simultaneous interpreting in a Word document. She gave not only detailed comments on word choices but also general comments on how to approach interpreting. (R13)

A teacher required us to send her an audio-recording of our consecutive interpreting and source texts for an assignment. She marked every part of the text where my performance was not satisfactory and made suggestions. She would leave a one-sentence critique at the top of the page and encouraging comments at the bottom. I still keep them, since they are memorable. (R14)

\subsubsection{Self-review based on audio/video recordings}

With respect to the advantages of self-review of one's own performance, students commonly answered that it gave them a different perspective, enabling them to see themselves more objectively. Those who felt that the self-review of a video-recorded interpreting performance had a strong effect, stated that they could somewhat objectively evaluate their own performance. Most of those respondents who gave positive feedback on the value of video recordings noted that these provided a lot of information on the performance aspect, including their posture during presentation. One student commented 
that it was good shock therapy. Some of the responses provided by participants are given below:

I can put myself in the listener's shoes and identify problems that I didn't realise before listening to my own interpreting. (R5)

I can't monitor myself well while I'm interpreting. It is more important to have a self-review than to go through the motions of practising with other students. (R13)

I can detect parts that not discussed or addressed before, and by doing this selfanalysis I can further study myself, looking for better ways to put them into the target language or parallel texts for reference. (R22)

By keeping records of my own performance, I can keep track of my progress and lack of progress. (R49)

I am the best judge of my own performance. (R7)

Those who were less enthusiastic about the effect of reflective practice based on monitoring their own interpreting gave the following reasons:

It's too stressful/distressing to listen to my own interpreting. (R2)

I know my errors and inadequate delivery without having to listen to audio recordings. (R34)

Interestingly, one respondent thought very highly of the effect of selfreview based on video recordings, even though she had not engaged with this method. Among those who assessed the effect of this method as 'medium', eight commented that they had never done it. These students did not seem to acknowledge the value of video recordings perhaps thinking instead that audio recordings are good enough. Some of their responses appear below:

What's seen is important, but what counts the most is contents. (R5)

There is not much different in terms of effect between audio and video, given the time and effort spent on recording. (R15)

Video-recording your own performance may not be important during training. Knowledge-building is more important. Performance can improve after two years of training because competence exudes confidence and then naturally leads to good performance. There may be exceptions, but those with bad performances may have already failed the entrance examination. (R27)

\section{Conclusions}

Feedback plays a crucial role in interpreter training, although interpreter trainers may sometimes take it for granted because it is such a routine part of everyday teaching and learning. This paper sought postgraduate student interpreters' feedback on the feedback generated by different actors and of different types through an online questionnaire-based survey, in order to examine the current feedback practices and how this affects student learning. Despite the limitations of our research methodology, the results clearly demonstrate that students value various types of feedback and appreciate these 
feedback experiences. The participants in the study reported on here valued teacher feedback far more than other types of feedback, considering it comprehensive yet specific, and more effective in helping them to realise their strengths and weaknesses. The data analysis also revealed that students want teachers' attention and support to focus on both of their academic and emotional needs. Participants' perceptions of the value of self-feedback indicates the value of autonomous learning in interpreter training, but also point to the need to raise awareness of the usefulness of video-based selfreview, and the need to promote more in-class discussion on peer feedback and its value.

For effective feedback practice, it is necessary for teachers and students to engage in dialogue on feedback and make optimal use of it. Värlander (2008: 154) recommends involving students in 'feedback preparation activities' and 'feedback-on-the-feedback' to allow active discussion between teachers and students with regard to the role of feedback, how to provide and receive feedback, and the emotions related to it. Teachers need to support the development of students' sense of agency and responsibility through feedback, which may be facilitated by building trusting relationships with students and sensitivity in handling students' emotional responses and psychological needs (Yang \& Carless 2013: 292).

The findings also suggest that we need to take a multidimensional view of feedback that considers both the situational and individual characteristics of the teaching/learning context and the nature and quality of feedback (Shute 2008: 176). Mastery of interpreting skills depends to a great extent on learners' ability to proactively take charge of their learning agenda, to make deliberate, goal-directed efforts to attain necessary skills and to achieve a degree of autonomy that will enable them to continue their journey to success beyond the classroom and the teacher (Brown and Lee 2015: 75). Therefore, it is important to create learning environments that promote both individual and collaborative learning, and that involve learners' interactions with their peers, teachers and diverse interpreting settings, thereby situating knowledge in a way that is appropriate to the targeted skill (Moser-Mercer 2008: 10).

In recent years, computer-assisted training has also been adopted to support learning in interpreter training (e.g., Secară et al. 2009; Moser-Mercer et al. 2005; Lim 2013; Lim 2014; Lee et al. 2015; Lee \& Huh 2015; Sandrelli 2015 ) and this can be incorporated in the provision of feedback. As traditional ways of teaching and learning are complemented by technology-enhanced interactions or computer-mediated feedback with the development of information technology, it would be worthwhile to examine how computermediated feedback differs from face-to-face interactions and how interpreter trainers can ensure the former effectively reinforces learning. Further research is also needed to examine actual interactions in class and outside of class, both in consecutive and simultaneous interpreting classes, and to investigate how we can further enhance students' learning experiences through feedback. 


\section{References}

Bangert-Drowns, R. L., Kulik, C.-L. C., Kulik, J. A., \& Morgan, M. T. (1991). The instructional effect of feedback in test-like events. Review of Educational Research, 61(2), 213-238. http://dx.doi.org/10.3102/00346543061002213

Bartłomiejczyk, M. (2007). Interpreting quality as perceived by trainee interpreters: Self-evaluation. The Interpreter and Translator Trainer, 1(2), 247-267.

Brown, H. D. \& Lee, H. (2015). Teaching by principles: An interactive approach to language Pedagogy ( $4^{\text {th }}$ edition). White Plains, NY: Pearson.

De Luque, M. F. S. \& Sommer, S. M. (2000). The impact of culture on feedbackseeking behavior: An integrated model and propositions. Academy of Management Review, 25(4). 829-849. doi: 10.5465/AMR.2000.3707736.

Duijnhouwer, H. (2010). Feedback effects on students' writing motivation, process and performance (Unpublished Doctoral dissertation). Utrecht: Utrecht University.

Fedor, D. B., Davis, W. D., Maslyn, J. M. \& Mathieson, K. (2001). Performance improvement efforts in response to negative feedback: The roles of source power and recipient self-esteem. Journal of Management, 27, 79-97.

Ficchi, V. (1999). Learning consecutive interpretation: An empirical study and an autonomous approach. Interpreting, 4(2), 199-218. doi: 10.1075/intp.4.2.04fic

Gile, D. (2005). Teaching conference interpreting: a contribution. In M. Tennent (Ed.), Training for the new millennium. Amsterdam/Philadelphia: John Benjamins Publishing Company.

Golke, S., Döfler, T. \& Artelt, C. (2015). The impact of elaborated feedback on text comprehension within a computer-based assessment. Learning and Instruction, 39, 123-136.

Hamer, J. Purchase, H. Luxton-Reilly, A. \& Denny, P. (2015). A comparison of peer and tutor feedback. Assessment \& Evaluation in Higher Education, 40(1), 151164. doi: 10.1080/02602938.2014.893418.

Hattie, J. (2012). Visible learning for teachers. Maximizing impact on learning. New York: Routledge.

Hattie, J. \& Timperley, H. (2007). The power of feedback. Review of Educational Research 77(1): 81-112. doi: 10.3102/003465430298487.

Horváth, I. (2007). Autonomous learning: what makes it work in postgraduate interpreter training?. Across Languages and Cultures, 8(1), 103-122.

Hounsell, D. (2003). Student feedback, learning and development. In M. Slowey, \& D. Watson (Eds.), Higher education and the lifecourse. Buckingham: SRHE \& Open University Press.

Kiraly, D. (2000). A social constructivist approach to translator education empowerment from theory to practice. Manchester: St. Jerome Publishing.

Kwark, J. C. \& Hong, S. Y. (2012). Thongpenyektayhakwenuy thongyek swuep mohyeng: hyeplyekhaksup cwungsimuy yenghan swunchathongyek kanguy yenkwu (In search of a teaching model for graduate-level conference interpreter training- Focusing on collaborative learning in the English-into-Korean consecutive interpreting classroom]. Tongbenyeokhakyenkwu (Interpreting and Translation Studies), 16(2), 85-114.

Lee, J. (2008). Rating scales for interpreting performance assessment. The Interpreter and Translator Trainer, 2(2), 165-184.

Lee, J., and Huh, J. (2015). Thongyekkyoyukuy pocotokwuloseuy SNS hwalyong salyey yenkwu- KakaoGroup-ul hwalyonghan smart learning (A case study of Smart Learning using an SNS, KakaoGroup in interpreter training). Thongpenyekhakyenkwu (The Journal of Interpretation and Translation Education), 13(1), 147-175.

Lee, J., Huh, J., Choi, M. and Chang, A. (2015). Blended learning-ul hwalyonghan tongyeok kyosubeb salyeyeongu (A case study of application of blended learning in conference interpreter training). Beonyeokhakyeongu (The Journal of Translation Studies), 16(1), 117-144.

Lim, L. (2013). Examining students' perceptions computer-assisted interpreter training. The Interpreter and Translator Trainer, 7(1), 71-89.

Translation \& Interpreting Vol 10 No 1 (2018) 
Lim, S. J. (2014). Thongyek haksupcatuluy pangkwa hwu cakicwuto haksuppwunsek: kulwup suthetilul cwungsimulo (Analysis of students' self-directed learning after class: with focus on group studies). Penyekhakyenkwu (The Journal of Translation Studies), 15(5), 181-220.

Liu, N. \& Carless, D. (2006). Peer feedback: The learning element of peer assessment. Teaching in Higher Education, 11(3), 279-290.

Moser-Mercer, B. (2000). The rocky road to expertise in interpreting: Eliciting knowledge from learners. In M. Kadric, K. Kaindl \& F. Pöchhacker (Eds.), Translationswissenschaft. Festschrift für Mary Snell-Hornby zum 60. Tübingen: Geburtstag.

Moser-Mercer, B. (2008). Skill acquisition in interpreting. The Interpreter and Translator Trainer, 2(1), 1-28. doi: 10.1080/1750399X.2008.10798764.

Moser-Mercer, B., Class, B. \& Seeber, K. (2005). Leveraging virtual learning environments for training interpreter trainers. Meta 50(4). Retrieved 12 December 2016 from http://id.erudit.org/iderudit/019872ar .

Narciss, S. \& Huth, K. (2004). How to design informative tutoring feedback for multimedia learning. In H. M. Niegemann, D. Leutner, \& R. Brunken (Eds.), Instructional design for multimedia learning. Munster, NY: Waxmann.

Nicol, D.J., \& Macfarlane-Dick, D. (2006). Formative assessment and self-regulated learning: A model and seven principles of good feedback practice. Studies in Higher Education, 31(2), 199-218.

Pridemore, D. R. \& Klein, J. D. (1995). Control of practice and level of feedback in computer-based instruction. Contemporary Educational Psychology, 20, 444450.

Riccardi, A. (2002). Evaluation in interpretation: Macrocriteria and microcriteria. In E. Hung (Ed.), Teaching translation and interpreting 4: Building bridges. Amsterdam \& Philadelphia: John Benjamins.

Russo, M. (1995). Self-evaluation: the awareness of one's own difficulties as a training tool for simultaneous interpretation. The Interpreters' Newsletter, 6, 7585.

Sadler, D. R. (1989). Formative assessment and the design of instructional systems. Instructional Science, 18, 119-44.

Sandrelli, A. (2015). Becoming an interpreter: The role of computer technology. MonTI Special Issue 2: 111-138. doi: 10.6035/MonTI.2015.ne2.4

Schjoldager, A. (1996). Assessment of simultaneous interpreting. In C. Dollerup \& V. Appel (Eds.), Teaching translation and interpreting 3: New horizons. Amsterdam \& Philadelphia: John Benjamins.

Scott, S. V. (2014). Practising what we preach: towards a student-centred definition of feedback. Teaching in Higher Education, 19(1), 49-57. doi: 10.1080/13562517.2013.827639.

Setton, R. and Dawrant, A. (2016). Conference interpreting: A trainer's guide. Amsterdam/Philadelphia: John Benjamins.

Secară, A., Pascaline M. \& Ramírez, Y. (2009). What's in your blend?: Creating resources for translator training. The Interpreter and Translator Trainer, 3(2), 275-294.

Shin, J., Lee, Y. \& Seo, E. (2016). The effects of feedback on students' achievement goals: Interaction between reference of comparison and regulatory focus. Learning and Instruction, 49, 21-31.

Shute, V. J. (2008) Focus on formative feedback. Review of Educational Research, 78(1), 153-189. doi: 10.3102/0034654307313795.

Takeda, K. (2010) What interpreting teachers can learn from students: A case study. Translation \& Interpreting, 2(1), 38-47.

Van Dam, I. M. (1989). Strategies of simultaneous interpretation. In L. Gran \& J. Dodds (Eds.), The theoretical and practical aspects of teaching conference interpretation. Udine: Campanotto Editore.

Värlander, S. (2008). The role of students' emotions in formal feedback situations. Teaching in Higher Education, 13(2), 145-156. doi: 10.1080/ 13562510801923195. 
Victori, M. \& Lockhart, W. (1995). Enhancing metacognition in self-directed language learning. Systems 23(2), 223-234.

Voerman, L., Fred A. J. K., Paulien C. M., \& Robert J. S. (2014). Feedback revisited: Adding perspectives based on positive psychology: Implications for theory and classroom practice. Teaching and Teacher Education, 43, 91-98. doi: 10.1016/j.tate.2014.06.005.

Wang, K. \& Han, C. (2013). Accomplishment in the multitude of counsellors: Peers feedback in translation training. Translation \& Interpreting, 5(2), 62-75.

Wiliam, D. (2007). Keeping learning on track: Classroom assessment and the regulation of learning. In F. K. Lester Jr. (Ed.), Second handbook of mathematics teaching and learning. Greenwich, CT: Information Age Publishing.

Yang, M. \& Carless, D. (2013). The feedback triangle and the enhancement of dialogic feedback processes. Teaching in Higher Education, 18(3), 285-297. doi: 10.1080/13562517.2012.719154.

Yang, S. H. (2012). Designing a Moodle based blended learning model for KoreanSpanish interpreting and translation class (Korean). Estudio Hispanico, 62, 9-35. 